\title{
Mentorship: Sustaining Knowledge in the Facilities Management Profession
}

\section{Mr. Jake Smithwick, Arizona State University}

Jake is a Researcher and Educator in the Del E. Webb School of Construction at Arizona State University (ASU). He received his degrees in Computer Information Systems and Construction Management, and spent six years in the US Air Force (Emergency Management). Jake works with owners, contractors, designers/engineers, and other agents in value-based project delivery, on a variety of delivery methods. He has supported over 250 projects totaling $\$ 600 \mathrm{M}$ of project value, in diverse scopes (new construction, tenant improvement, software services, health insurance, commodities, and others), at a wide range of public and private organizations (school districts, cities, counties, states, universities, manufacturers). Jake has given 100 presentations to more than 3,000 people throughout the United States and Canada. $\mathrm{He}$ is finishing a PhD in Construction Management and a Master of Public Administration (MPA). His research focuses on a flexible model for managing and optimizing construction overhead expenses.

\section{Ms. Kristen Caroline Hurtado, Arizona State University}

Kristen Hurtado, MS, LEED AP (O+M), Fulbright Scholar, is a PhD student in Construction Management in the School of Sustainable Engineering and the Built Environment at Arizona State University (ASU). Currently, Kristen's research is in the fields of measurement of adult learning in the built environment and how that relates to organizational change management. She is a lecturer and project manager at the Performance Based Studies Research Group (PBSRG), at ASU. Kristen has her undergraduate and graduate degrees in Construction Management, with an emphasis on Facilities Management from ASU. In her career, she has had the opportunity to work in the building industry for large international contractors, owners, consulting entities, and recently as an educator in the field. She has seen projects in the public, private, transportation, health, and manufacturing sectors. While also pursuing her $\mathrm{PhD}$, Kristen is also working towards another graduate degree in Education and Instructional Design.

\section{Anna Thurston, Arizona State University}

Anna Thurston is a Master's student at Arizona State University with professional experience in the optimization of the building life cycle and Strategic Facility Planning. She earned a Bachelor of Science in Urban and Environmental Planning from Arizona State University in 2013 and is currently pursuing a Master of Science in Construction Management with a focus in Facility Management. She is passionate about the Built Environment and is committed to industry improvement, the application of sustainable practices and helping to foster student enrollment into the industry.

Prof. Kenneth Timothy Sullivan PhD, Arizona State University 


\section{Mentorship: Sustaining Knowledge in the Facilities Management Profession}

\section{Introduction}

Mentorship has been shown to enhance career progression and learning of all parties involved. Mentorship can take place between individuals with different organizational positions (i.e., an executive and the new junior salesperson), or even different levels of experience (a new hire with 20 years' experience at another job and the new hire straight out of college). Mentorship is a powerful tool due to its reciprocal nature: both parties gain mutual benefit through participation in the transaction. The mentee learns more about their profession or industry, while the mentor may gain new perspectives on their field, or perhaps a different way of explaining a certain nuance of the job. Mentoring relationships also have the effect of helping the younger person gain an identity and the proper socialization within an organizational context. Social learning theory postulates that people enhance their cognitive skills in social environments, either through direct observation of a certain behavior or through modeling what others do.

From these simple constructs, the reader may also deduce that mentorship has positive ancillary benefits for an entire industry. One field that would highly benefit from increased use of mentoring educational experiences is the operation and maintenance of existing structures (i.e., facilities management). A 2010 survey of 169 facility managers found the profession does not have a well-defined career path from entrance to retirement ${ }^{7}$. Currently, there are 27 accredited FM degree programs throughout the world ${ }^{5}$. In regards to succession planning within the FM profession, 64 percent of the survey's respondents reported that they do not have a succession plan in place. The survey respondents also reported that 49 percent were planning to retire in 10 years (73 percent retiring in 15 years). The summation of these data (lack of formal education programs, no long term succession planning, and an impending massive retirement of FM professionals) necessitates an immediate response that provides new entrants with some of the institutional and technical knowledge of the soon-to-be-retired FM professionals. The authors propose that student-industry mentorship helps address the problem.

Over the past 18 months, the researchers collaboratively developed a mentorship program between a local International Facility Management Association (IFMA) student chapter, their sponsoring professional chapter, and the University. Students and industry mentors are aligned based on their mutual interests and expertise, and participate in a wide array of activities: coaching, job shadowing, resolving challenges, and project meetings. In the pilot year of the program, half of the student participants received paid full-time employment upon graduation. The paper presents results of a survey that the authors distributed to the local IFMA chapter to further develop the mentorship program. This paper builds on previous work ${ }^{6}$ and will specifically focus on hiring characteristics in FM field, and the profession's perception of a mentorship program.

\section{Literature Review}


Mentoring can be defined as a process wherein a mentor and mentee work in collaboration to uncover and develop the mentee's understanding, skills, and competence in a particular area 9 . Further classifications by type of mentorship can be derived, such as role model or facilitative ${ }^{9}$, leader-member exchange, organizational citizenship behavior, social support, or socialization ${ }^{8}$. A majority of the existing mentoring interventions take place within organizations as a means to prepare internal job candidates for promotion to senior executive positions and stimulate succession planning ${ }^{8,9,10}$. The benefits of industry mentorships for students is another value adding intervention and has the potential to bridge the knowledge gap created by large volumes of retirement by preparing the future workforce.

As previously mentioned, retirement is a global and localized threat to industries such as facilities management as they look to fill the growing gap in experience-based knowledge. Consequently, a solution has been to delay retirement for those with more senior positions and experience. In 2014, Building Operating Management's annual FM Pulse survey of 3,200 facility managers found 18 percent delayed retirement because of the economy, while 22 percent have 5 years or less until they retire ${ }^{11}$.

In 2010, the National Resource Council estimated that 42 percent of the Senior Executive Service retired ${ }^{5}$. This same study also identified challenges that organizations have in the shifting culture dynamics of a younger population. Though this study focused on federal agencies, these challenges are very much applicable across many industries. With many seasoned professionals and experts preparing to retire, there will be increased need for organizations to replace this loss of institutional knowledge. The NRC proposed that the Facility Managers of tomorrow will need to understand the life-cycle costs of assets, alignment of people and resources with the organizations strategic objectives, and serve as the key liaison between multiple departments as the organization advances its goals.

Another challenge that Facility Managers face is planning for how they will actually transition themselves out of the organization upon retirement. Only 36 percent of the respondents from the aforementioned nationwide survey identified that they have a succession plan in place ${ }^{7}$. This plan needs to consider how personnel progress through their careers. Figure 1 shows the relative importance of various skillsets as people develop in their career. 


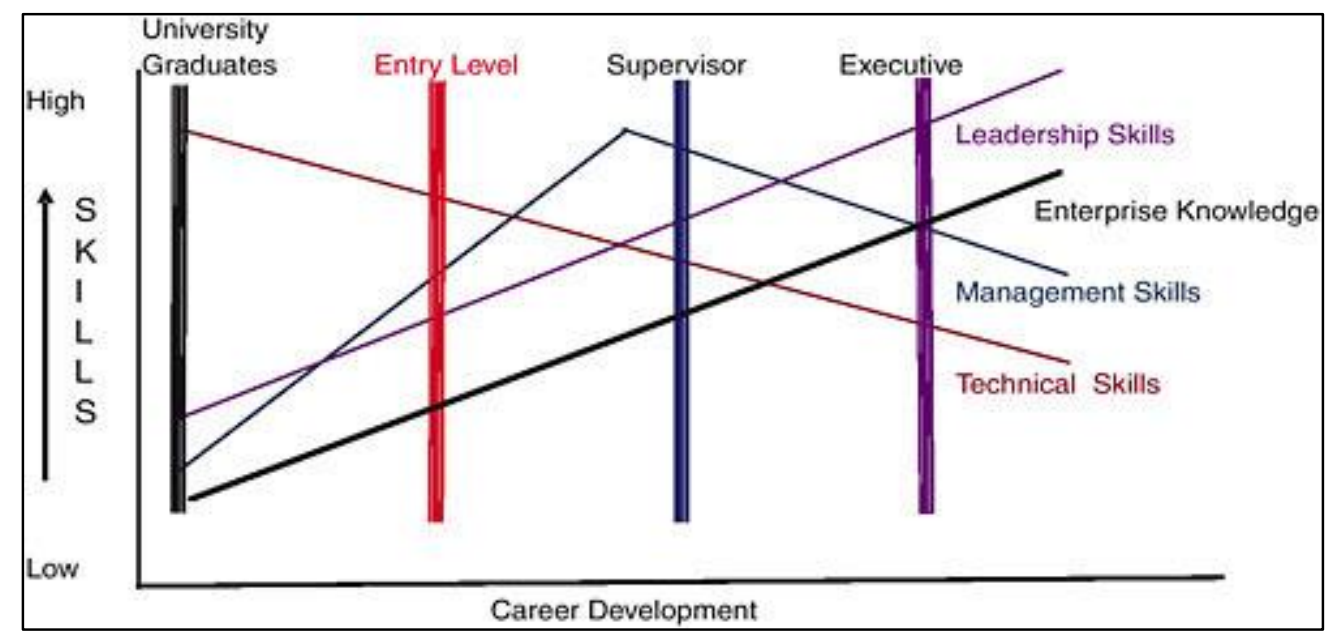

Figure 1. Career Development of Skillsets ${ }^{1}$.

Noticeably, there is a need to address the growing need for FM professionals in the future. One way to provide this new supply of FMs is a mentorship program that exposes students to the industry, while they are still pursuing their postsecondary education. Fundamentally, mentorship helps the participants build a mutual relationship founded on their common goals and support of the given profession ${ }^{2}$. A successful mentorship is one where the understudy works with an experienced individual who is willing to share their knowledge. The mentor is a role model, and the mentee / student observes their behavior and attempts to take on some of the mentor's characteristics.

Mentoring is a highly social, and intentional, interaction between two individuals. Social learning theory provides sound justification for why mentorship can be very successful. Much of the reader's own knowledge are likely based on some form of observed behavior of others ${ }^{2}$. Furthermore, social learning is not a one-way process: both people in the interaction get something from the relationship. The reciprocal nature of learning is an essential part of mentorship ${ }^{4}$. Both the mentor and student must have a desire to learn from each other. This is not to say that they both get the same thing; rather, having an open mind and minimizing unfair expectations of the other person can greatly improve the quality of the mentorship.

\section{Mentorship Model}

One key idea that the literature review revealed is that the most successful mentorships are longterm (100 or more hours) with a structured set of activities ${ }^{2}$. The time commitment was of particular interest to the researchers: this substantial time requirement seemed to indicate that any time spent in the mentoring function should be well-planned. Another way to view the 100 hour time commitment within a four-year term is that it represents a two hour monthly meeting, or perhaps ten hours each month for ten months. The researchers' own personal experiences and personal discussions with the mentors identified that such a high time commitment was not feasible. The researchers found that two hours per month for one year was a reasonable expectation for both students and mentors. 
The mentorship model presented below in Figure 2 is specifically designed to emphasize industry and practical experiences by leveraging the use of an industry mentor. While a monthly lunch meeting or weekly coffee meeting certainly has merit, the engagement and learning derived from the suggested activities (hands-on projects, job shadowing, etc.) is higher.

There are four components of the model:

1. Express interest by submitting a mentorship informational form. Students and mentors can sign-up to participate in the program by filling out a form that describes their interests and goals. The student chapter leadership will attempt to align students with mentors based on what their mutual interests might be.

2. Planning meeting. Once the student chapter leadership makes an introduction, the student and mentor should meet and plan out specifically what they want to accomplish during their mentorship. This planning meeting should identify actionable goals, activities, and a tentative schedule.

3. Mentoring. While some students only may only want to meet for a single semester, the most successful mentorships take place over the course of at least one year. The mentor and student should regularly review their plan and make any updates as necessary.

4. Documentation and Closeout. At the conclusion of a mentorship, both parties should compile their major lessons learned and experiences. The student will especially benefit as they might be able to use this information for future job interviews and cataloguing of their major hands-on experiences.

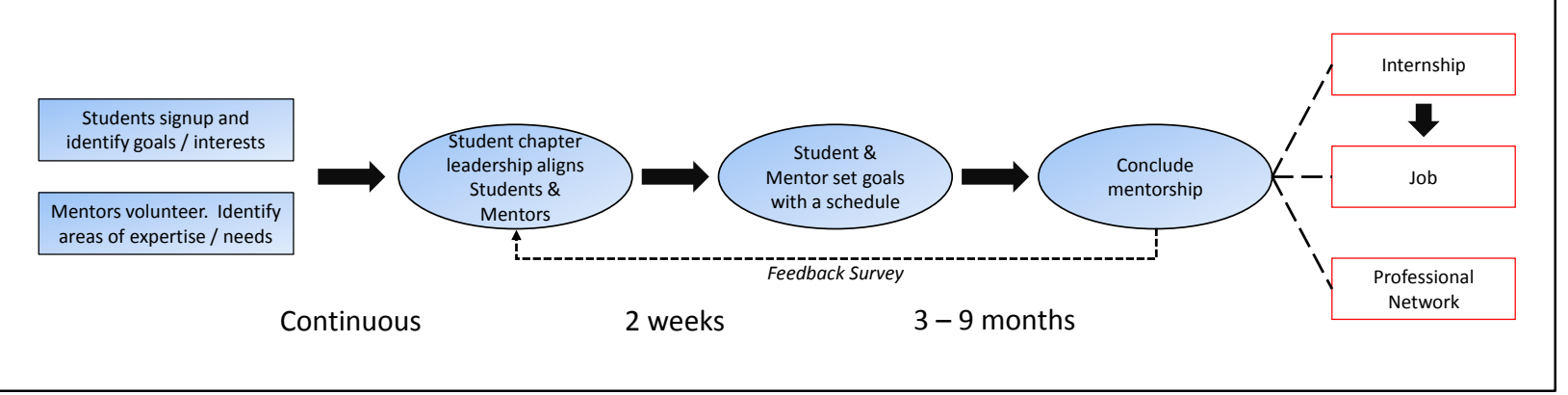

Figure 2. Student-Mentor Model $^{6}$

\section{Survey Results: FM Hiring Practices}

The researchers had high initial success with the first pilot year of the new mentorship program ${ }^{6}$. In particular:

- There were 14 volunteer mentors and eight student mentees

- Four student mentees received some sort of career advancement through a postgraduation hiring or paid internship 
- 100 percent of survey respondents would recommend other people participate in the program

- Overall 8.4 out of 10 satisfaction with the program

There were two important takeaways from the first year of the mentorship program. First, each mentorship team needs to have a clear plan for what they will accomplish over the duration of the mentorship. This was already part of the model (see Figure 2), but some of the teams did not take time to setup a plan. Teams that did not have a plan struggled to find mutually beneficial activities, and were somewhat unsatisfied with program. The second major lesson learned was that students need to keep a log of their experiences. The benefits are twofold: it helps them capture what they learned in an organized system, and it also encourages new students to participate in the program. During the pilot year of the program, none of the students formally documented their experiences with the program.

While the first year was marked with great success, the researchers were concerned that more students and professionals did not participate in the program. While the literature has shown (and what has essentially become common knowledge in the profession) that there is a strong need for new FM professionals, the job market may be out of alignment with the skills of people that can actually fill the positions. Students have shared anecdotal stories with the researchers that they have looked for FM jobs, but the skill and experience requirements are far beyond what the students currently possesses. Likewise, professionals have informally expressed that they would like to hire people, but it's "always hard to find the right person." Clearly, there is a gap between what students can offer and what the FM industry is wanting to hire.

The researchers conducted a short survey (see Appendix 1) of a local International Facility Management Association (IFMA) chapter to try and begin understanding how people are hired into the FM organization. The survey was handed out during the registration and sign-in for a monthly IFMA chapter meeting. The survey was distributed by the chapter's administrator. A total of 34 people returned a survey.

Figure 3 shows the demographics of the survey sample. Professional members are classified as facility managers and are generally considered the key stakeholders in the IFMA organization. Associate members are vendors or suppliers that offer various services to Professional members. The survey respondents were: 39 percent Professional members and 61 percent Associate members. Over half of the people surveyed have ten years of experience or fewer working in the FM field (regardless if Associate or Professional members). 


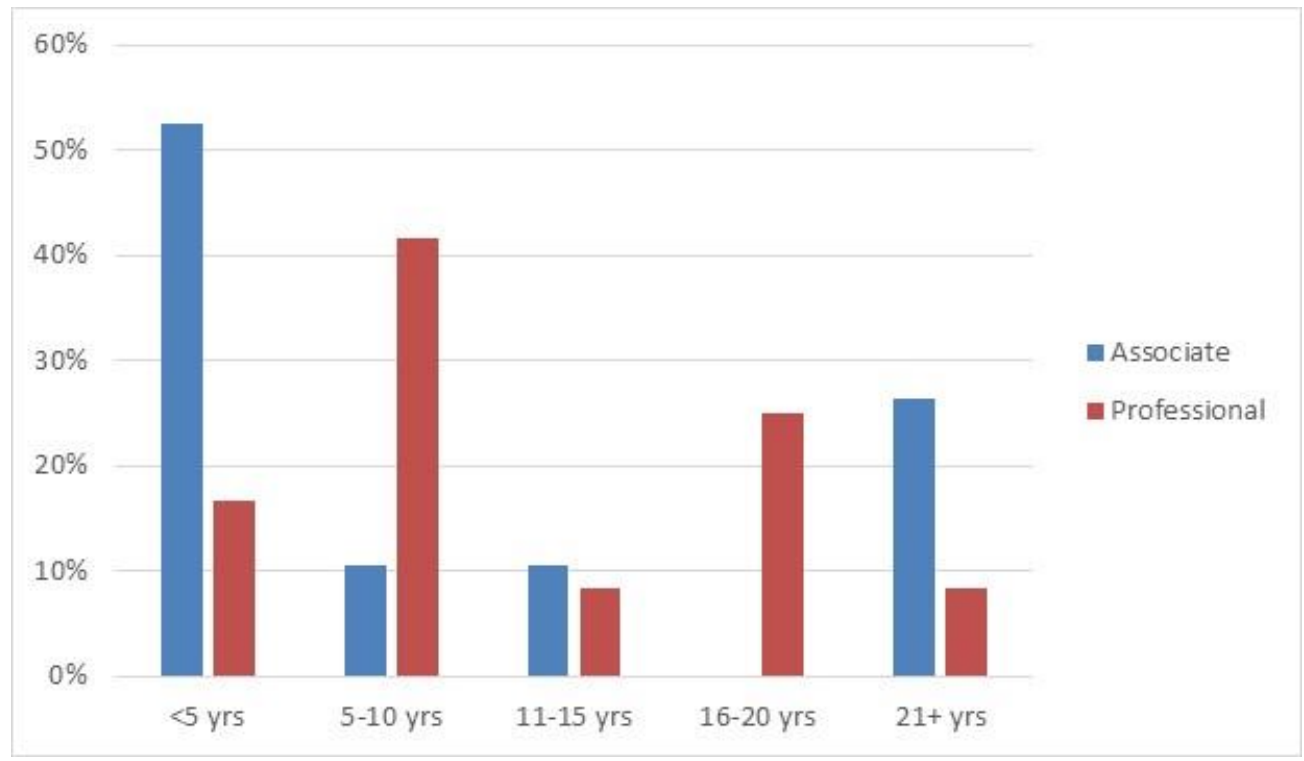

Figure 3. Frequency demographics of sampled group.

Next, Figure 4 presents the sampled group's source from where they typically hire people. The respondents reported that 74 percent of new hires were external to their organization. Figure 5 shows by what criteria organizations consider the most important criteria hiring new personnel.

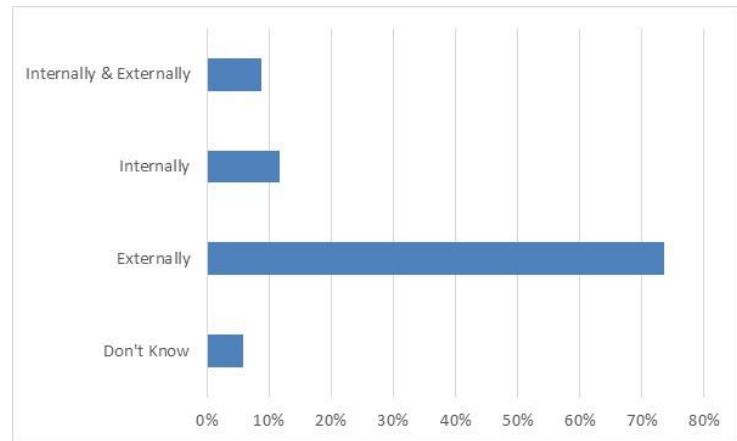

Figure 4. Where new hires come from.

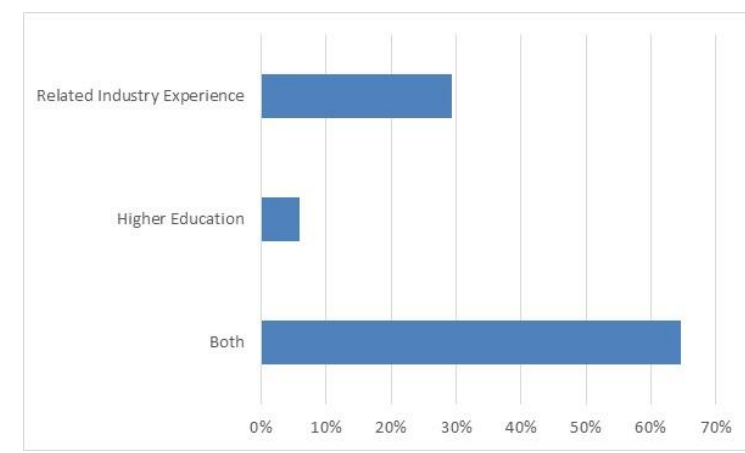

Figure 5. Hiring criteria.

Finally, the researchers asked respondents to rate, on a scale from 1 to 9 , the importance of hands-on experience was for new-hires (with "9" being "very important"). The mean and median rating was 8 .

\section{Discussion}

The survey results, albeit from a limited sample, indicate several interesting trends. First, a very large majority of new-hires are external to the organization. This bodes very well for students, as many of them will be external to their first post-college position in Facility Management. Evaluating this criteria on its own indicates that there may be relatively few barriers to entrance for students. However, the new-hire criteria (Figure 4) suggests that students without some hands-experience in the FM field may be at a large disadvantage when trying to get hired. Of course, this in and of itself is a not groundbreaking revelation: organizations certainly would prefer to generally hire people with past experience (than those with no experience). What 
Figures 4 and 4 do show, however, is the importance for students to actively seek out opportunities to gain experience. The mentorship model presented offers these opportunities, and has positive results for the participants.

\section{Conclusion}

The primary objective of this research study was to identify the needs to sustain the Facility Management profession during this time of immense demographic change. It is well documented that a large majority of the highly seasoned FM professionals will be retiring in the next ten years. Their retirement will leave a void of knowledge and experience that could negatively impact owner organizations if the situation is not addressed with haste.

A well-structured mentorship program between higher institutions of education and professional organizations is one viable way to begin to support future FM professionals. Research has shown that both mentors and students can reap significant benefits from fostering a professional relationship. The mentorship model presented here, and in previous studies, is well-supported at a local IFMA chapter level and partnering University. The initial survey results indicate that hands-on experience is an important aspect when making hiring decisions. A mentorship program can help provide some of the hands-on experience.

\section{Future Research}

The researchers' personal observations and the initial industry survey might be an indication of misaligned expectations in terms of who FM organizations want to hire, and who they actually have available. One hypothesis is that organizations hiring in FM may be trying to hire those with similar experience as those who are retiring. This certainly does not minimize the value of firsthand experience, but it might be an unsustainable model. Further research is needed regarding how FM organizations actually hire, and the criteria used to select a new hire. These results can then be used to improve higher education curricula so that students are being educated and are honing their skills to be competitive to FM organizations looking to hire new graduates. Further, mentorship programs can also benefit from these results by using them to refine and expand mentorship activities, such as coaching, job shadowing, resolving challenges, and project meetings.

\section{Bibliography}

1. Badger, W., and J. Smith. 2006. Great Leadership Skills and Traits: The Faculty's Secret Enabler. Proceedings of the $2^{\text {nd }}$ Specialty Conference on Leadership and Management in Construction, Grand Bahamas, May 4-6.

2. Denson, C. D., \& Hill, R. B. (2010). Impact of an Engineering Mentorship Program on African-American Male High School Students' Perceptions and Self-Efficacy. Journal of Industrial Teacher Education, 47(1), 99-127. 
3. FM Accredited Degree Program Directory. (n.d.). Retrieved January 10, 2015, from http://foundation.ifma.org/academics/fm-accredited-degree-program-directory

4. Kram, K. E., \& Isabella, L. A. (1985). Mentoring Alternatives: The Role of Peer Relationships in Career Development. Academy of Management Journal, 28(1), 110.

5. NRC (National Research Council). 2008. Core Competencies for Federal Facilities Asset Management Through 2020. Washington, D.C.: National Academy Press.

6. Smithwick, J., Thurston, A., Hurtado, K., Kashiwagi, D., \& Sullivan, K. (2014). Student Engagement in the Facility Management Profession through Mentorship. International Journal of Facility Management, 5(2)

7. Sullivan, K., Georgoulis, S. W., \& Lines, B. (2010). Empirical study of the current United States facilities management profession. Journal of Facilities Management, 8(2), 91-103. doi:10.1108/14725961011041143

8. McManus, S. E. \& Russell, J. E. A. (1997). New directions for mentoring research: an examination of related constructs. Journal of Vocational Behaviors, 51, 145-161.

9. Nayab, N. (2010). The role of mentoring in effective succession planning. Retrieved on 14 March 2015, from http://www.brighthub.com/office/humanresources/articles/95270.aspx

10. de Janasz, S. C., Sullivan, S. E., \& Whiting, V. (2003). Mentor networks and career success: Lessons for turbulent times. Academy of Management Executive, 17(4), 78-91.

11. Maas, A. (2014). FM pulse and salary survey. Facilities Net. Retrieved on 14 March 2015, from http://www.facilitiesnet.com/facilitiesmanagement/article/How-FacilityManagers-Handle-Increasing-Workload-Shrinking-Budget-Staff--15289? source=part 


\section{Appendix 1 - Facilities Industry Background Survey}

\section{Facilities Industry Background Survey}

A. How many years have you worked in the facility management industry?

$\square<5$ years $\square 5-10$ years $\square 11-15$ years $\square 16-20$ years $\square 21+$ years

B. Are you a professional or associate member of IFMA?

$\square$ Professional [i.e., facility manager] $\square$ Associate [i.e., vendor]

C. From where do you most often hire new personnel into your organization?

$\square$ Internally [i.e., another department] $\square$ Externally [i.e., public job postings] $\square$ Don't Know

D. Please rate the following statement on a scale from 1 to 9 , with 1 being "not important" and 9 being "very important."

\begin{tabular}{|l|c|}
\hline Criteria & Your Rating \\
\hline The IFMA student chapter is developing a mentorship program to help students get & \\
more hands-on experience and training with the FM profession. How important is \\
hands-on experience for new-hires in the FM profession?
\end{tabular}

E. Which of these factors is the most important when making hiring decisions in facility management?

$\square$ Related industry experience $\square$ Higher education $\square$ Both are equally important

F. Would you like to learn more about the mentorship program? If so, please provide your contact information below: 